\title{
Assessment of a concrete arch bridge using static and dynamic load tests
}

\author{
B. Ozden Caglayan, Kadir Ozakgul* and Ovunc Tezer \\ Department of Civil Engineering, Istanbul Technical University, 34469 Maslak, Istanbul, Turkey \\ (Received December 22, 2009, February 18, 2011, Accepted December 13, 2011)
}

\begin{abstract}
Assessment of a monumental concrete arch bridge with a total length of 210 meters having three major spans of 30 meters and a height of 65 meters, which is located in an earthquake-prone region in southern part of the country is presented in this study. Three-dimensional finite element model of the bridge was generated using a commercially available general finite element analysis software and based on the outcomes of a series of in-depth acceleration measurements that were conducted on-site, the model was refined. By using the structural parameters obtained from the dynamic and the static tests, calibrated model of the bridge structure was obtained and this model was used for necessary calculations regarding structural assessment and evaluation.
\end{abstract}

Keywords: concrete arch bridge; dynamic test; model calibration; impact factor; rating factor

\section{Introduction}

Arch bridges are mostly known as structures using masonry as the load carrying system. There are also arch bridges that employ plain concrete, relying on compressive strength characteristics of the material. In the last decades, various studies have been conducted by researchers on the response and evaluation of masonry and concrete arch bridges under different actions.

Application of finite element tools for assessment of arches was outlined by Boothby and Atamturktur (2007) with detailed instructions related to geometric and solid models as well as meshing and implying boundary conditions. Results of full-scale tests were used to calibrate 3D finite element models of stone arch bridges by Fanning and Boothby (2001) and reasonable set of assumptions were given for accurate computer modeling. Another article summarizes the findings related to transverse soil pressures on spandrel walls of masonry arches due to heavy truck loads (Fanning et al. 2001).

Behaviour of filled masonry arch bridges with spans of 3 to 12 meters was examined by Boothby et al. (1998) by service load testing and calibrated finite element models. Static, dynamic and longterm in-situ tests were done by Frýba and Pirner (2001) on highway bridges and stresses were monitored under usual traffic loads. Marefat et al. (2004) conducted static and dynamic tests to find out the remaining load carrying capacity of a plain concrete arch bridge. Their tests revealed that all parts of the arch bridge (spandrel wall, pier, foundation, etc.) contributed to the structural performance and

*Corresponding author, Ph.D, E-mail: ozakgulk@itu.edu.tr 
the bridge acted like a continuous structure rather than a simple arch form.

A methodology for the dynamic-based assessment of a reinforced concrete arch bridge was presented by Gentile (2006). This approach was based on ambient vibration testing, output-only modal identification and updating of the uncertain structural parameters of a finite element model of the bridge. In a study by Robert-Nicoud et al. (2005), a model calibration method was proposed based on structural behaviour such as support conditions and material properties. Brencich and Sabia (2007) used dynamic tests on a masonry bridge to identify the natural frequencies and mode shapes of the bridge and conducted compressive tests for the comparative characterization of the brickwork. Material test results were used to set up finite element models, so that the reliability of the material characterization procedures is demonstrated by comparison between the dynamic tests and finite element model results.

In this study, model identification of the bridge structure is obtained by using measurement data from dynamic and static tests. Following these tests, refined model of the bridge was generated based on test results and these models were used for structural assessment and evaluation of the bridge structure.

\section{Location and description of the bridge}

The railway infrastructure of Turkey dates back to mid-to-late 19th century and has approximately 8600 kilometers of track length, divided into seven major regions, all run by TCDD (Turkish Railways Administration) which is a governmental organization. Various structural types of railway bridges are available throughout this railway network, such as steel trusses, reinforced concrete bridges, concrete arch and masonry arch bridges, due to rough character of geographical conditions of the country. Among these, masonry arch bridges have a special standing, because they provide an elegant architectural structure that appeals both professionals and non-professionals.

One of these bridges is the monumental Hacikiri bridge, having eleven spans of $3 \times 36+3 \times 14.75+$ $16.88+2 \times 12.25+11.45+9.45$ meters summing up to a total length of 215 meters (see Fig. 1). The bridge is a mass concrete arch bridge with masonry cladding. It was designed and built in 1912 by German design contractor Philipp Holzmann AG in order to transport soldiers, goods and passengers, and

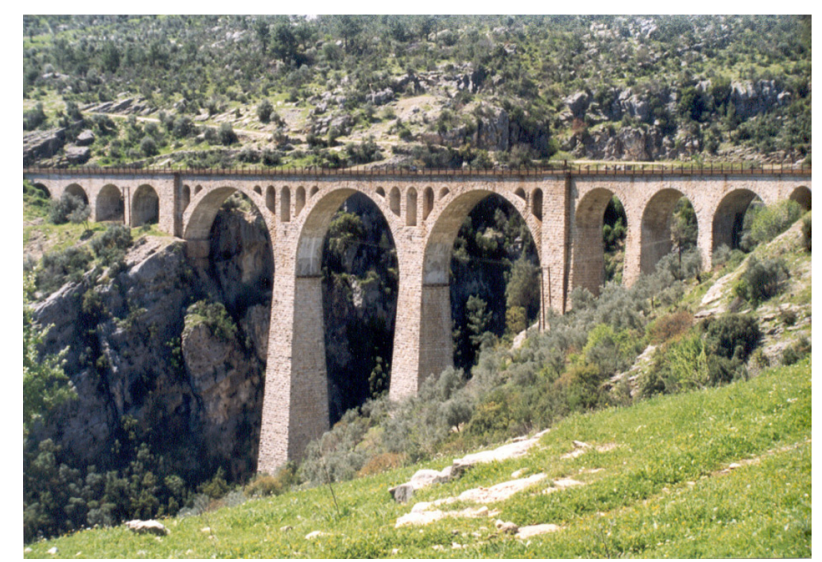

Fig. 1 General view of the Hacikiri bridge 


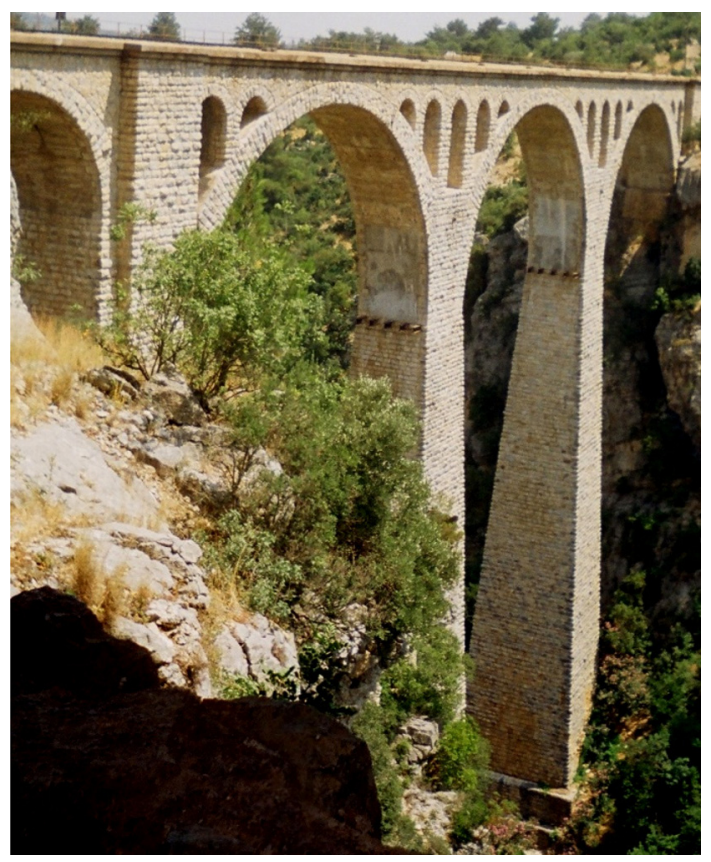

Fig. 2 Detail view of spans of $36 \mathrm{~m}$

as well as to gain access to oil resources. Near the bridge location, Germans built 22 long tunnels (so-called the Taurus tunnels) with a total length of $12 \mathrm{~km}$ and also many railway bridges spanning over the deep valleys, with the Hacikiri bridge as the most important of them all with a height of 65 meters and \% 19 slope. Therefore, the bridge deserves a special interest due to its architectural and glorious view. The structure is located in an earthquake-prone region, however it still continues to give service with no apparent damage albeit recent nearby earthquakes.

In Fig. 2, views of piers, arch barrel and spandrel wall, and pier-abutment related with critical locations of the bridge are given more closely.

\section{Dynamic load tests on the bridge}

Test train provided by TCDD was employed as the excitation mechanism for the bridge. In order to obtain dependable data, the test train was used eight times to record the acceleration response. Each recorded data corresponds to the free vibration of the bridge once the train has passed and left the bridge. Number and locations of accelerometers were determined with the use of the initial finite element model that had been previously developed based on the as-built constructional drawings and design calculations. As mode-shapes could not be obtained in longitudinal direction in this pre-assessment phase, accelerometers were mounted on the bridge only for the transversal and vertical directions. Pre-selected locations of single and bi-axial accelerometers on the bridge are depicted in Fig. 3. A single accelerometer unit is shown below in Fig. 4. Dynamic parameters were obtained using the mean values of these eight tests. 


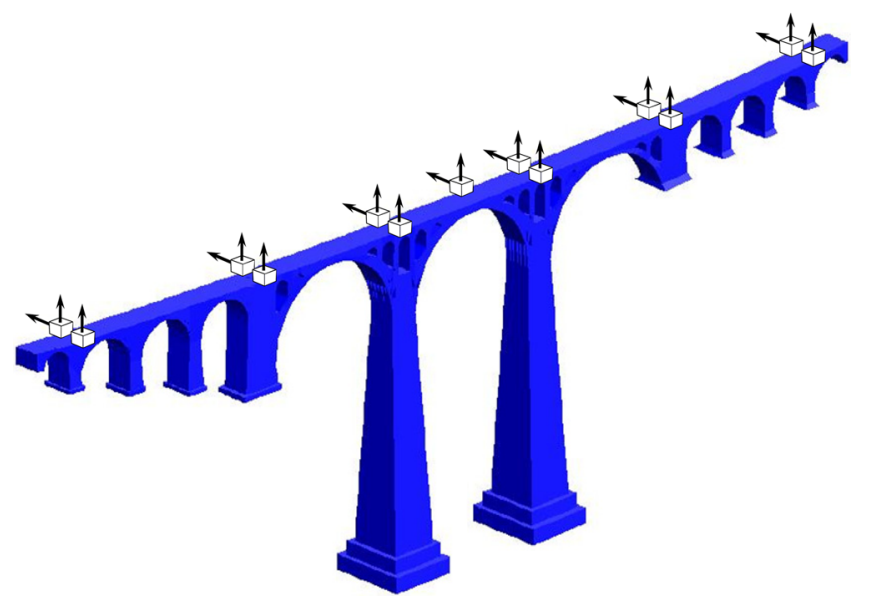

Fig. 3 Layout of accelerometers shown on the finite element model of the bridge

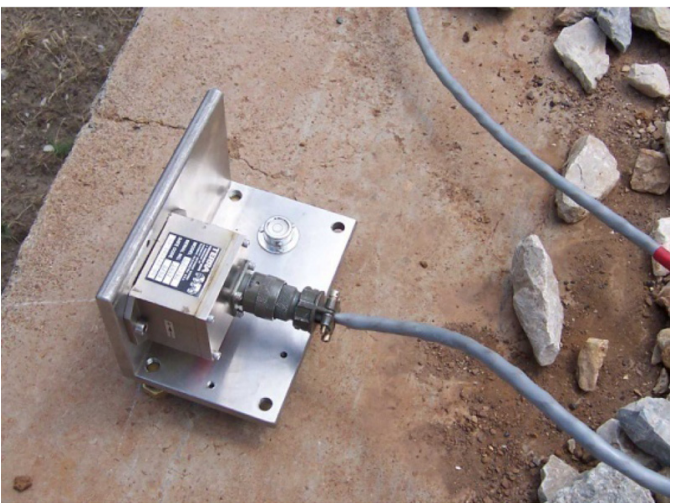

Fig. 4 Single axial accelerometer unit

The identification of the most significant natural frequencies of the bridge was based on a spectral approach in the frequency domain. For that purpose, the Normalized Power Spectral Density (NPSD) functions associated with every measurement channel were estimated. According to Felber (1993), the NPSD functions are defined as

$$
\operatorname{NPSD}_{i}\left(f_{k}\right)=\frac{P S D_{i}\left(f_{k}\right)}{\sum_{k=0}^{k=n} P S D_{i}\left(f_{k}\right)}
$$

in which, $f_{k}$ is the $k$ th discrete frequency and $n$ is the number of discrete frequencies.

Fig. 5 shows normalized spectra (NPSD) obtained in the range $0-18 \mathrm{~Hz}$, related with the transversal and vertical accelerations.

An inspection of the peak values of these spectrum have enabled easy identification of the relevant natural frequencies of the structure.

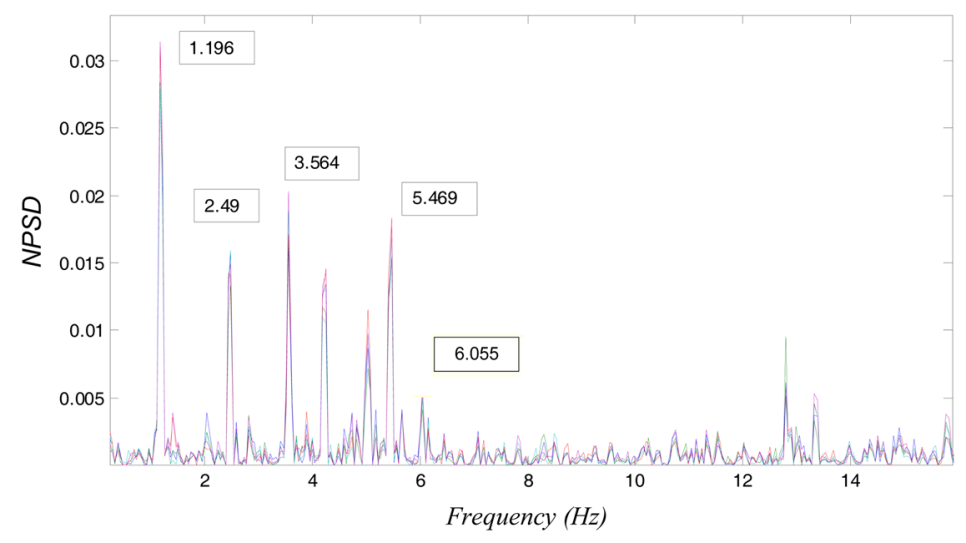

Fig. 5 Normalized spectra (NPSD) 
Table 1 Comparison of dynamic characteristics calculated from the measured accelerations and identified FEM of the Hacikiri bridge in $\mathrm{Hz}$

\begin{tabular}{cccc}
\hline \hline $\begin{array}{c}\text { Mode } \\
f\end{array}$ & $\begin{array}{c}\text { Frequencies obtained from } \\
\text { FE model }\end{array}$ & $\begin{array}{c}\text { Frequencies found by } \\
\text { experimental studies }\end{array}$ & $\begin{array}{c}\text { Experimental damping } \\
\text { ratios (\%) }\end{array}$ \\
\hline 1 & 1.169 & 1.196 & 2.20 \\
2 & 2.350 & 2.490 & 1.80 \\
3 & 3.447 & 3.564 & 1.30 \\
4 & 5.715 & 5.469 & 1.00 \\
5 & 6.270 & 6.055 & 0.89 \\
\hline
\end{tabular}

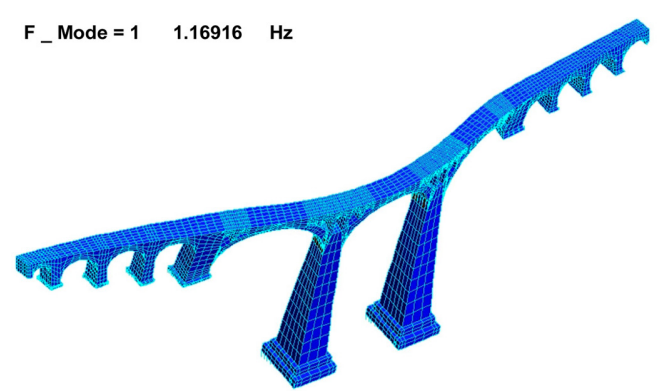

$F_{-}$Mode $=3 \quad 3.44687 \quad \mathrm{~Hz}$

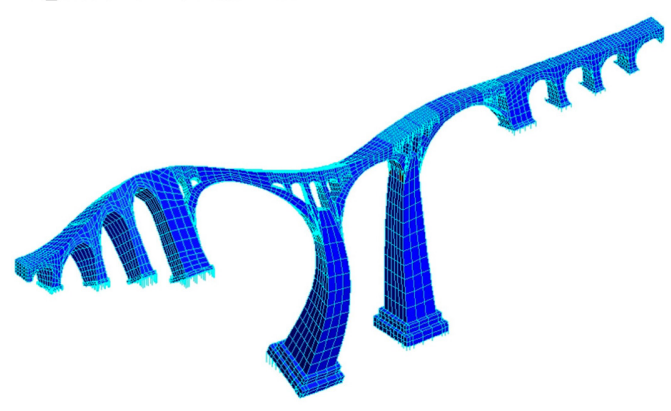

$F_{-}$Mode $=5 \quad 6.26978 \mathrm{~Hz}$

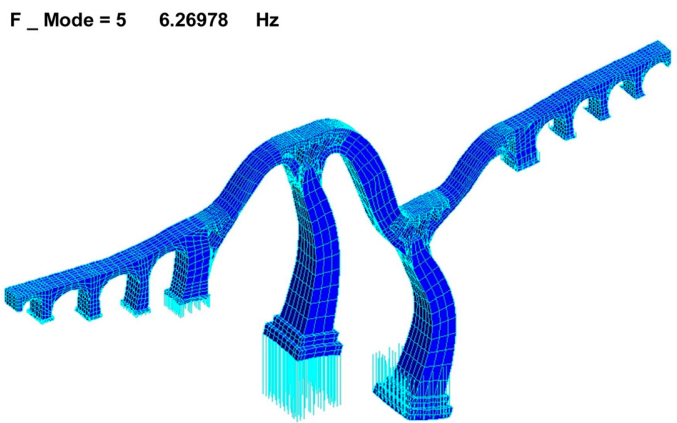

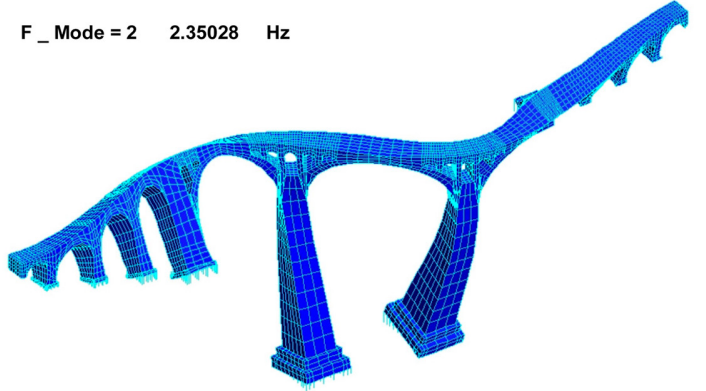

$F_{-}$Mode $=4 \quad 5.71542 \mathrm{~Hz}$

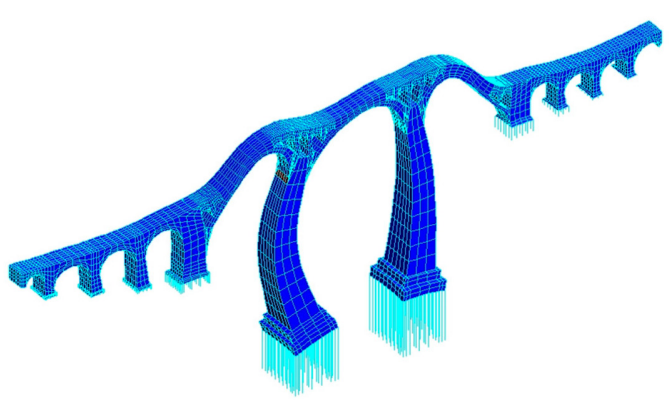

Fig. 6 First five mode shapes of the bridge obtained by numerical analysis

Mode shape vectors corresponding to individual natural frequencies were computed by using Potential Modal Ratio (PMR) function as described by Felber (1993). This function has enabled rapid processing of test data. 
First five natural frequencies and corresponding mode shapes are given in Table 1 and Fig. 6, respectively.

As can be seen from Fig. 6, mode shapes found by numerical analysis are bending and mixed (bending+torsional) modes in the transversal and vertical directions.

To obtain damping ratio from frequency domain, half-power bandwidth method was employed. In this commonly used method, frequency response function (FRF) amplitude of the system is obtained first. Using the peak value, each natural vibration frequencies of the structural system are obtained. More detail about the procedure is available in the book by Nashif et al. (1985).

\section{Static load tests on the bridge}

For the static load tests, two diesel locomotives of DE24000 type were used and the static load positions are shown in Fig. 7 below. In this field study,because of impossible conditions of the ground surface crossed by the bridge, vertical displacement measurement on the bridge was performed by using tiltmeter instead of LVDTs. Under static test loadings, slope values at selected bridge deck points were measured by using tiltmeters (see Fig. 8).

As proposed by Sanli et al. (2000), the vertical displacement values were obtained from measured slopes. In order to eliminate measurement errors, as many tiltmeter readings as possible must be made for each measurement point under the test load. The average values of these measurements within a $90 \%$ confidence limit are used to define vertical displacements.

In the same article by Sanli et al. (2000), a numerical procedure based on a cubic spline technique is presented for calculating the vertical displacement of a bridge structure depending on the tiltmeter readings under specific external test load. For the cubic spline technique, an optimization technique has been used which employs a Sequential Quadratic Programming method, along with the numerical procedure which constructs the cubic smoothing splines to the given data.

Before the external test loading, tilt measurements are obtained as the initial reference values at each instrumented bridge deck locations. After applying external loading, tilt measurements are collected again for the same locations. For each bridge deck measuring points the difference between two tilt measurements corresponds to the tilt values solely caused by the external loading.

Initial values of the vertical displacements are estimated from the slope values that measured from the unloaded position at the loaded bridge deck points where slopes are measured using tiltmeters

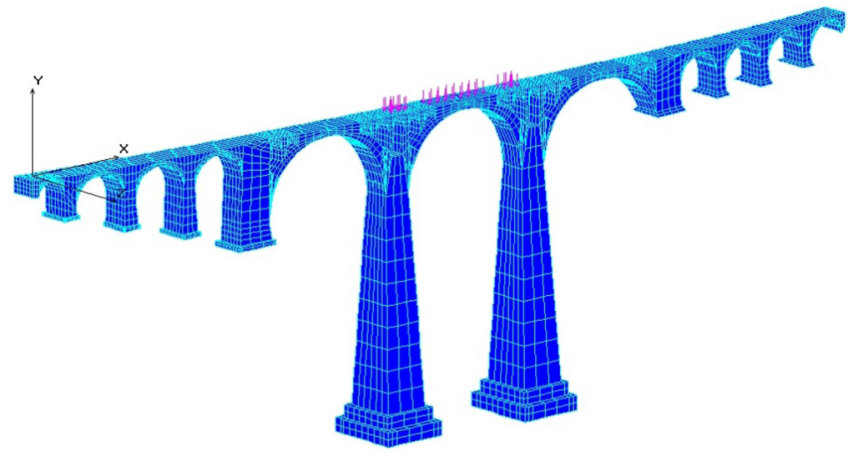

Fig. 7 Static test loading of the Hacikiri bridge

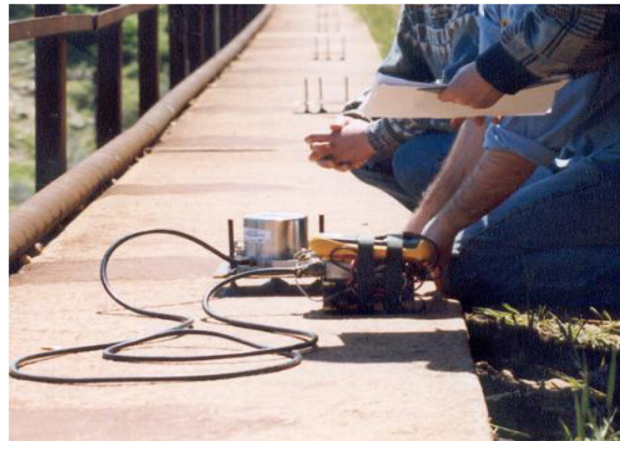

Fig. 8 Tilt measuring system 


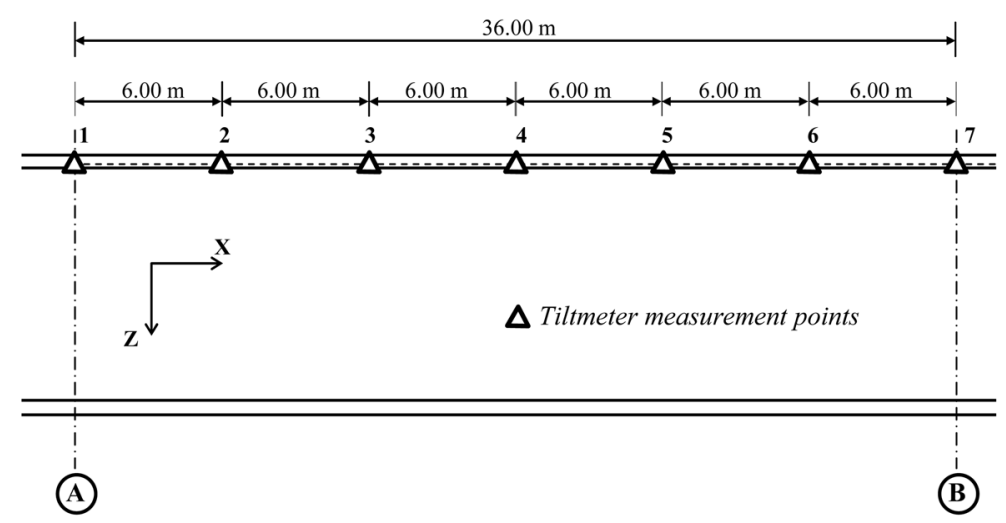

Fig. 9 Tiltmeter measurement points on the Hacikiri bridge (plan view)

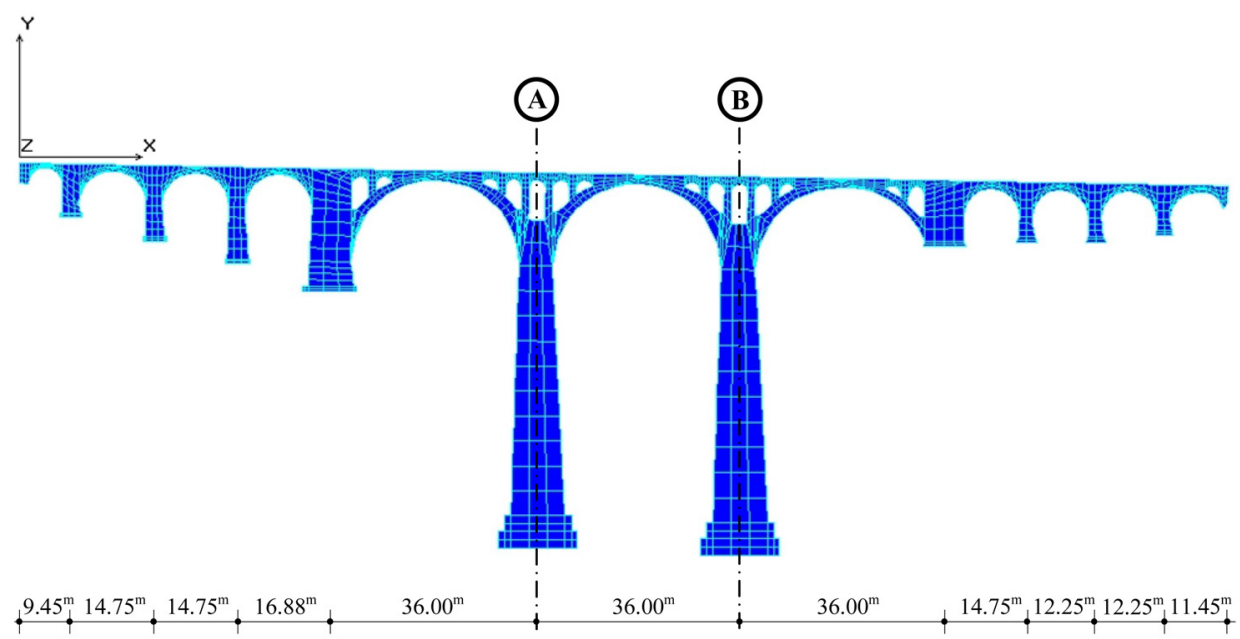

Fig. 10 Elevation of the Hacikiri bridge

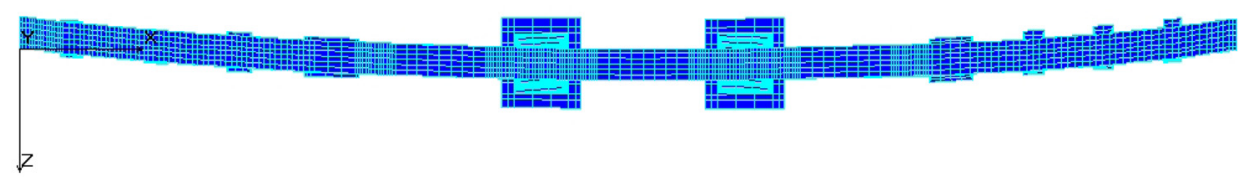

Fig. 11 Plan view of the Hacikiri bridge

under the test load. Then, the cubic smoothing spline is completely defined for the selected initial data. In the third step, the sums of the squares of the difference between the measured and calculated slope values using the defined cubic spline function is minimized. For this purpose, a procedure generally referred to as constrained nonlinear optimization which uses a Sequential Quadratic Programming technique is employed using MATLAB (2009). After completion step three, depending on the final spline function constructed, actual vertical displacements of the bridge at any location can be easily defined (Sanli et al. 2000).

Vertical displacements obtained at measuring points, see Figs. 9-11, and along with the others obtained numerically for the same points using the identified finite element model of the bridge (for 
Table 2 Displacements obtained from the measured tilts and identified finite element model of the Hacikiri bridge $(\mathrm{mm})$

\begin{tabular}{ccc}
\hline \hline Measurement points & $\begin{array}{c}\text { Displacements obtained from } \\
\text { FE Model }\end{array}$ & $\begin{array}{c}\text { Displacements obtained from } \\
\text { the measured tilts }\end{array}$ \\
\hline 1 & 0.0000 & 0.0000 \\
2 & -0.4136 & -0.4100 \\
3 & -0.9168 & -0.9200 \\
4 & -1.2900 & -1.2880 \\
5 & -0.8342 & -0.8300 \\
6 & -0.4033 & -0.4000 \\
7 & 0.0000 & 0.0000 \\
\hline
\end{tabular}

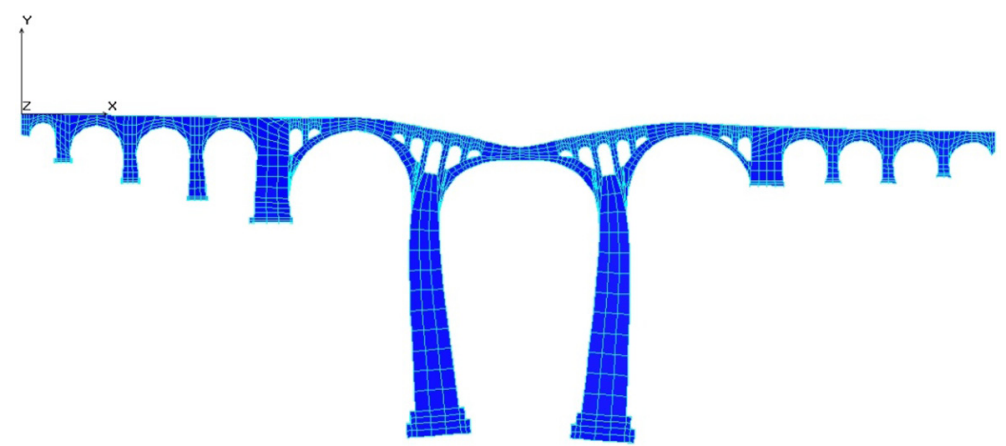

Fig. 12 Exaggerated deflected shape of the bridge under static loading

detailed description, see following sections) are presented in Table 2. Bridge deflection shape obtained by finite element computer model are presented in Fig. 12.

Very close agreement was reached between the vertical displacement values that have been obtained from measured slopes, and those obtained via computer analysis of the bridge at the same locations.

\section{Finite element modeling of existing bridge}

Throughout this study, general finite element software COSMOS/M has been employed for modeling the structure (COSMOS/M 2008). The prepared finite element model that is used has a total of 9440 isoparametric solid (8-node brick) and gap elements with a total of 13634 nodes and 40347 degrees-of-freedom. The connections between beam elements used for simulating rails on the bridge and solid elements were carried out by using the gap elements. All the models rest on springs and elements are connected to lateral and vertical supports by rigid bars at their corresponding member ends. Visual inspections have shown no sign of cracks on the bridge, therefore in numerical modelling phase, cracks were not taken into account.

As noted earlier, Hacikiri bridge is a mass concrete bridge. For this bridge, material test reports were not available and so as not to extract material samples from the bridge, Schmidt hammer was used in manholes to check the concrete quality. A total of 50 readings were recorded from different concrete surface areas that could be reached within the manholes. Average of rebound numbers was 


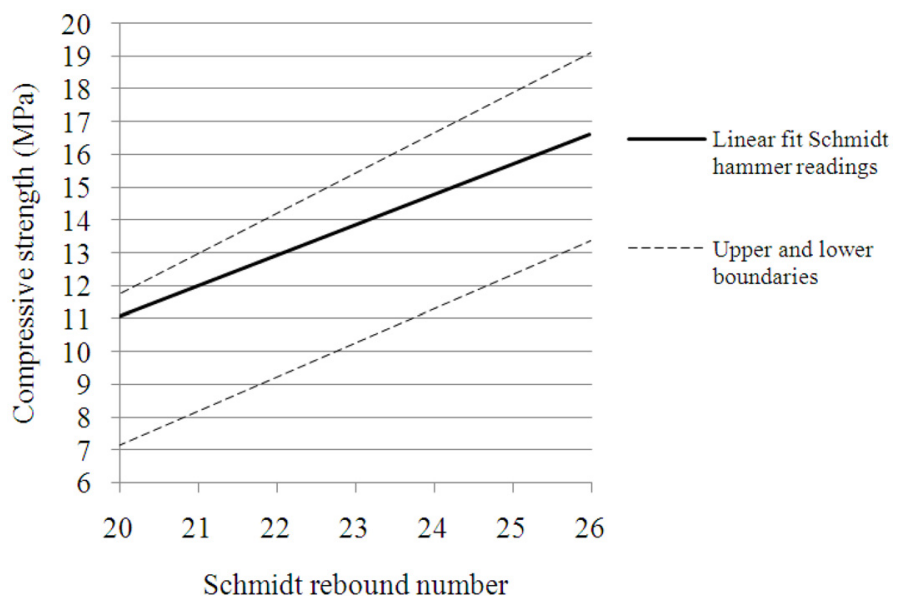

Fig. 13 Rebound numbers and strength relations

found as 25.5 and standard deviation was calculated as 1.6812. Linearly fitted curve along with upper and lower boundaries for Schmidt readings are given in Fig. 13 below.

Schmidt hammer results have yielded similar values to the strengths given in project documents. Based on this information, throughout the finite element analysis, concrete was assumed to have compressive strength of $14 \mathrm{MPa}$, modulus of elasticity of $20 \mathrm{GPa}$ and a density of $2300 \mathrm{~kg} / \mathrm{m}^{3}$.

Finite element model that will be used assessing the performance of the bridge cannot be used without calibrating. The initial model does not account for inherent variability of material properties and time-dependent stiffness changes, so, the initial FE model is calibrated by field ambient vibration test results. The model calibration is aimed to match the frequencies and mode shapes obtained from the field ambient vibration testing to the finite element results.

To realize the FE model calibration, the parametric study was first carried out and the sensitive parameters were observed. It is found bearing spring stiffness in the longitudinal and vertical direction, and joint lumped masses were the most sensitive parameters to structural dynamic characteristics. Thus, they were selected as the main calibration parameters in current study.

The finite element model calibration was carried out by adjusting those selected parameters until reasonable matches in the natural frequencies and modal shapes were observed. Only the most structurally significant modes and frequencies are used in the model calibration process till obtaining high $M A C$ (modal assurance criteria) values.

Because the springs at support points are located well far away from the critical points such as the crowns of the three larger spans, local calibration of the finite element models was performed based on tiltmeter (or so-called inclinometer) measurements under stationary loadings induced by a single locomotive.

Frequency analysis of the globally and locally calibrated finite element model was conducted and close agreement was obtained with the dynamic field test results. In Fig. 6 and Table 1, the mode shapes and frequency values of vibration of the bridge with the modal periods sufficiently close to the values given in Fig. 5 are given, respectively.

This refined finite element model was used to evaluate the load rating of the current condition of Hacikiri bridge according to proposed TCDD and UIC axle loads for the near future. 


\section{Load rating of the bridge}

Rating factor is one of the key parameters that define the status of a bridge and its response to various loads. Also it is possible to obtain the residual strength of the bridge superstructure and derive solutions in case of degradation.

In this study, a factor of load rating was determined to assess the remaining strength of the Hacikiri bridge. Rating factor (Marefat et al. 2004) is defined as the following ratio

$$
R F=\frac{\sigma_{a l l}-\sigma_{D L}}{\delta \cdot \sigma_{L L}}
$$

with the parameters as: $R F$, rating factor; $\sigma_{a l l}$, allowable stress of the structural material; $\sigma_{D L}$, stress under dead load; $\sigma_{L L}$, stress under live load, and finally $\delta$, impact factor.

Of these, $\sigma_{D L}$ and $\sigma_{L L}$ were computed with the help of refined computer model that was subjected to gravitational and specified live loads. Live loads were proposed by TCDD as, $(i)$ a freight train with two locomotives followed by 20 freight cars summing up to an approximate total length of 400 $\mathrm{m}$, and (ii) standard UIC-776-1 (UIC 1994) live load specification for a train with $250 \mathrm{kN}$ axle loads.

\subsection{Calculation of the impact factor of the Hacikiri bridge}

The impact factor, $\delta$ were taken as the ratio of the maximum dynamic compressive stress and the maximum static compressive stress obtained by performing a stepwise analysis of FEM model of the Hacikiri bridge (Frýba and Pirner 2001), as follows

$$
\delta=\frac{\sigma_{d y n}}{\sigma_{\text {stat }}}
$$

where, $\sigma_{d y n}$ is maximum compressive stress (see Fig. 14) under the test train traveling at normal speed, and $\sigma_{\text {stat }}$ is maximum static compressive stress (see Fig. 15) due to the static loading at the

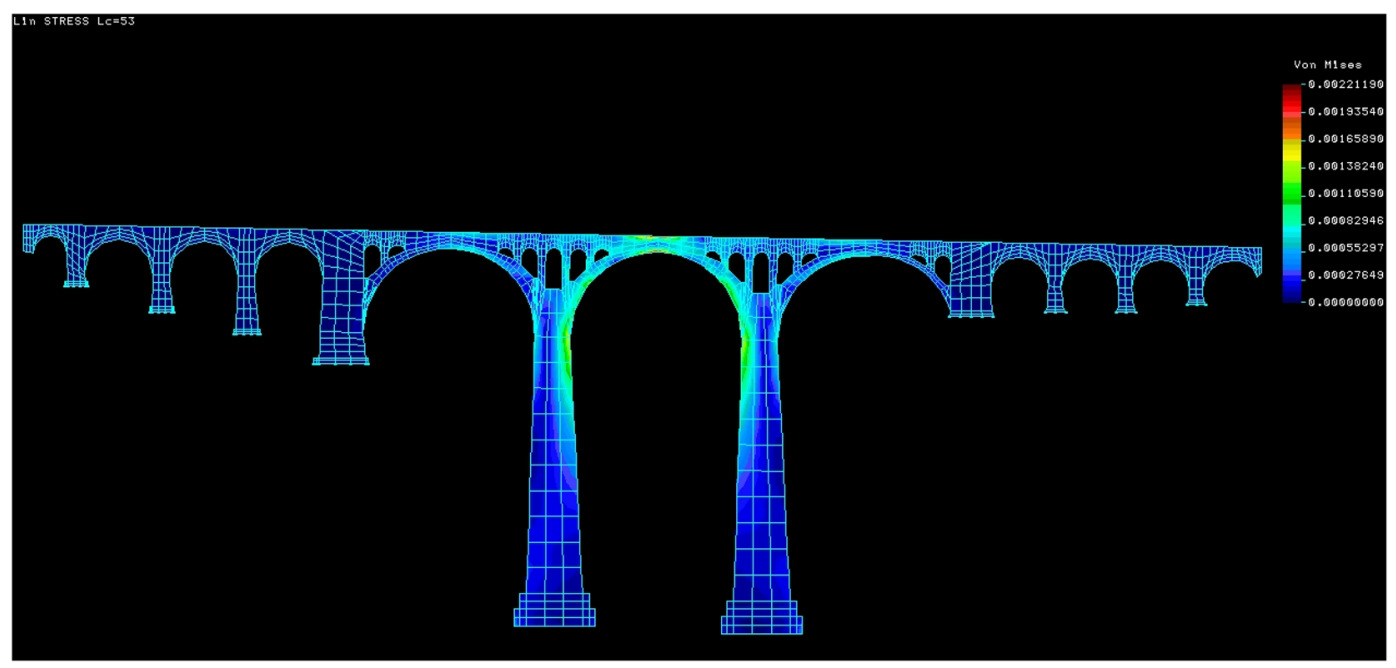

Fig. 14 Stress results under moving load 


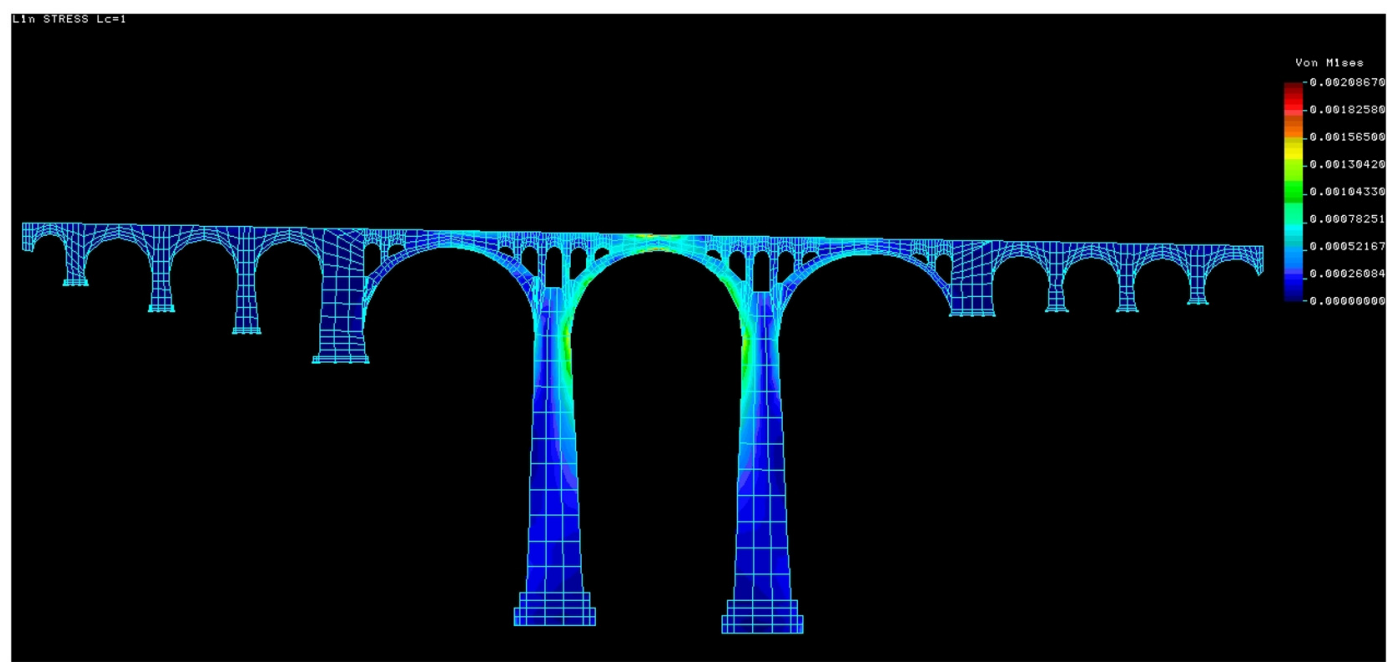

Fig. 15 Stress results due to static load

same point. The value of impact factor for this bridge is determined as of 1.06.

Due to limited number of publications on rating of concrete arch bridges, survey on impact factors for this type of bridges has had to be limited. In a journal article by Marefat et al. (2004), the authors note the effect of speed on impact factor and state that impact factor may be taken as 1.20 for speeds up to $60 \mathrm{~km} / \mathrm{h}$ and this value increases as the speed increases. Hacikiri bridge is situated just between two small train stations and due to operating regulations, trains have to stop at these stations before entering and after leaving the bridge. Due to this special operating conditions, trains do not cross the bridge with a speed more than $40 \mathrm{~km} / \mathrm{h}$. In addition, studies on Hacikiri bridge has shown that impact factor is limited to a maximum value of 1.15 for this bridge.

Analyses were conducted on the refined computer model with axle loads of TCDD and UIC train sets simulated as point loads, and critical stresses were obtained. These stress values along with aforementioned impact factor value of 1.06 have resulted in rating factors of 10.47 and 6.77 for TCDD and UIC train sets, respectively. Up to now, this historical bridge was used by Turkish Railways Administration according to S1950 train set (BE 1960) which is much heavier than UIC live load, and it can be expected that these large values may easily be attributed to these heavy design loads.

\section{Conclusions}

In this study, an efficient assessment procedure for a concrete or masonry arch bridge is presented. During tests, rail traffic is not suspended and transportation of freight and passengers is not interrupted. Another advantage of this procedure is that tests are independent of bridge height and clearance underneath.

Model identification of the bridge structure was obtained by using measurement data from the dynamic and the static tests. Calibrated model of the bridge was generated based on test results and this model is used for structural assessment and evaluation of the bridge structure.

The outcomes of the load rating procedure show that the bridge has the capability to withstand 
proposed train loads with considerable safety. However, due to historical heritage status of this massive structure, maximum care must be taken in operation as well as maintenance of this bridge.

\section{Acknowledgements}

Many thanks are owed to the technical staff of Turkish State Railways for their support during field trips to bridges.

\section{References}

BE (1960), Brechnungsgrundlagen für Stahlerne Eisenbahnbrücken, DB Deutsche Bahn, München.

Boothby, T. and Atamturktur, S. (2007), "A guide for the finite element analysis of historic load bearing masonry structures", Proceedings of the $10^{\text {th }}$ North American Masonry Conference, St. Louis, Missouri.

Boothby, T.E., Domalik, D.E. and Dalal, V.A. (1998), "Service load response of masonry arch bridges", J. Struct. Eng., ASCE, 124, 17-23.

Brencich, A. and Sabia, D. (2007), "Experimental identification of a multi-span masonry bridge: The Tanaro Bridge", Construct. Build. Mater., 22, 2087-2099.

COSMOS/M (2008), User's manual, Solidworks Corporation, Dassault Systèmes, Massachusetts.

Fanning, P.J. and Boothby, T.E. (2001), "Three-dimensional modeling and full scale testing of stone arch bridges", Comput. Struct., 79, 2645-2662.

Fanning, P.J., Boothby, T.E. and Roberts, B.J. (2001), "Longitudinal and transverse effects in masonry arch assessment", Const. Build. Mater., 15, 51-60.

Felber, A.J. (1993), "Development of a hybrid bridge evaluation system", PhD Thesis, Univ. of British Columbia, Canada.

Frýba, L. and Pirner, M. (2001), "Load tests and modal analysis of bridges", Eng. Struct., 23, 102-109.

Gentile, C. (2006), "Modal and structural identification of a R.C. arch bridge", Struct. Eng. Mech., 22(1), 53-70.

Marefat, M.S., Ghahremani-Gargary, E. and Ataei, S. (2004), "Load test of a plain concrete arch railway bridge of 20-m span", Constr. Build. Mater., 18, 661-667.

MATLAB 2009b (2009), Spline Toolbox and Optimization Toolbox, The Mathworks, Natick, MA.

Nashif, A., Jones, D. and Henderson, J. (1985), Vibration damping, John Wiley \& Sons, New York.

Robert-Nicoud, Y., Raphael, B., Burdet, O. and Smith, I.F.C. (2005), "Model identification of bridges using measurement data", Computer-Aided Civil Inf. Eng., 20, 118-131.

Sanli, A.K., Uzgider, E.A., Caglayan, O.B., Ozakgul, K. and Bien, J. (2000), "Testing bridges by using tiltmeter measurements", J. Transp. Res. Board., 1696, 111-117.

UIC (1994), UIC 776-1 Loads to be considered in railway bridge design, International Union of Railways Code, Paris. 